\title{
Effect of Magnetic Field on Some Physical Characteristics and Cetane Number of Diesel Fuel
}

\author{
Abdelnabi A. Elamin ${ }^{1}$, Mohamed Ezeldin ${ }^{2}$, Ali M. Masaad ${ }^{2}$, Nawal M. Suleman ${ }^{3}$ \\ ${ }^{1}$ Department of Physical, Faculty of Science and Technology, Omdurman Islamic University, Khartoum, Sudan \\ ${ }^{2}$ Department of Chemistry, Faculty of Science and Technology, Omdurman Islamic University, Khartoum, Sudan \\ ${ }^{3}$ Department of Chemistry, Zilfi Faculty of Education, Majmmah University, Zilfi, Saudi Arabia
}

Email address:

Wadalmsna3.com@gmail.com (M. Ezeldin)

\section{To cite this article:}

Abdelnabi A. Elamin, Mohamed. Ezeldin, Ali. M. Masaad, Nawal M. Suleman. Effect of Magnetic Field on Some Physical Characteristics and Cetane Number of Diesel Fuel. American Journal of Applied Chemistry. Vol. 3, No. 6, 2015, pp. 212-216.

doi: 10.11648/j.ajac.20150306.16

\begin{abstract}
The main objective of the present work was passing of diesel fuel on magnetic field produced by magnetic pole by $121 \mathrm{mT}$, to improve the physical properties of diesel fuel and cetane number $(\mathrm{CN})$, the diesel fuel produced from Khartoum refinery (Sudan). The physical characteristics and cetane number of used sample were tested according to American society for testing and materials (ASTM), physical properties included: Density, and kinematic viscosity. The cetane number of diesel used in this project was recorded (55.6) before passing on magnetic field, in the other hand the intensity of magnetic field was recorded $(121 \mathrm{mT})$. The physical properties of sample after the passing process were improved to the limits assigned by ASTM and Khartoum refinery. $\mathrm{CN}$ was increased to 60.3 .
\end{abstract}

Keywords: Diesel, Magnetic Field, Cetane Number, Density of Diesel, Viscosity of Diesel

\section{Introduction}

\subsection{Diesel}

Diesel, recognizing that the liquid petroleum byproducts might be better engine fuels than coal dust, began to experiment with one of them. This fuel change, coupled with some mechanical design changes, resulted in a successful prototype engine in 1895 (Gruseand Stevens, 1960). Today, both the engine and fuel still bear his name (Lee., et al, 2002). The first commercial diesel engines were large and operated at low speeds (Yamaki., et al, 2001). They were used to power ships, trains, and industrial plants. By the 1930s, diesel engines were also powering trucks and buses. An effort in the late ' 30 s to extend the engine's use to passenger cars was interrupted by World War II (Davis and Brenner., 2001).

After the war, diesel passenger cars became very popular in Europe; but, they have not enjoyed comparable success in the United States yet (Duncan, 2012). Today, diesel engines are used worldwide for transportation, manufacturing, power generation, construction, and farming. The types of diesel engines are as varied as their use - from small, high-speed indirect-injection engines to low-speed direct-injection behemoths with cylinders one meter (three feet) in diameter (Duncan, 2010). Their success comes from their efficiency, economy, and reliability, the subject of this review is diesel fuel - its performance, properties, refining, and testing. The review discusses diesel engines, especially the heavy-duty diesel engines used in trucks and buses, considering both the engine and fuel together as a system .Additionally, because environmental regulations are so important to the industry, there view examines their impact on both fuel and engine (Harris, 2010).

Cetane number $(\mathrm{CN})$ is a measure of the ignition quality of the diesel fuel and is carried by a standard engine test as specified by ASTM (ASTM, 2005). The ignition quality is determined by measuring the ignition delay, which is the period between the time of injection and the start of combustion (ignition) of the fuel (Isdale, 1976). A fuel with a high $\mathrm{CN}$ has a short ignition delay period and starts to combust shortly after it is injected into an engine. The ignition quality of the diesel fuel depends on its molecular composition. Some of the simpler molecular components such as the n-paraffins can ignite in a diesel engine with relative ease, but others like aromatics have more stable 
ring structures and so require higher temperature and pressure to ignite (Park and Irvine, 1984).The ASTM D6131test method defines the $\mathrm{CN}$ of a diesel fuel as the percentage by volume of normal cetane $(\mathrm{C} 16 \mathrm{H} 34)$, ina blend with 2,2,4,4,6,8,8-heptamethylnonane (sometimes called HMN or isocetane), which matches the ignition quality of the diesel fuel being rated under the specified test conditions. By definition, normal cetane has been assigned a $\mathrm{CN}$ of 100 , whereas $\mathrm{HMN}$ has a $\mathrm{CN}$ of 15 . The ASTM D613 method involves running the fuel in a single-cylinder compression ignition engine with a continuously variable compression ratio under a fixed set of conditions. Although it has been the traditional test method for $\mathrm{CN}$, it was soon recognized that the test suffer from many disadvantages, some of which include a relatively large fuel sample volume requirement $1 \mathrm{~L}$, significant time consumption (approximately a few hours), and a relatively high reproducibility error (ASTM, 2015).

\subsection{Effect of Magnetic Field on Fuel Molecules}

Hydrogen occurs in two distinct isomeric forms Para and ortho. It is characterized by the different opposite nucleus spins. The ortho state of hydrogen is more effective than para state for maximum complete combustion. The ortho state can be achieved by introducing strong magnetic field along the fuel line. Hydrocarbon molecules form clusters, It has been technically possible to enhance Vander Waals' discovery due to the application of the Magnetic field, a high power, permanent magnetic device strong enough to break down, i.e. de-cluster these $\mathrm{HC}$ associations, so maximum space acquisition for oxygen to combine with hydrocarbon (Govindasamy et al 2007).

Thus when the fuel flows through a magnetic field, created by the strong permanent magnets, the hydrocarbon change their orientation (para to ortho) and molecules of hydrocarbon change their configuration, at the same time inter molecular force is considerably reduced. This mechanism helps to disperse oil particles and to become finely divided. This has the effect of ensuring that the fuel actively interlocks with oxygen and producing a more complete burn in the combustion chamber. Figure. 1 shows the clusters of hydrocarbons changed with the influence of magnetic field and they are more dispersed.

\section{Materials and Methods}

\subsection{Materials}

All chemicals used were of analytical reagent grade (AR) and of highest purity degree available. They included cetane, iso octane, iso cetane and n-heptane, diesel sample was taken from Khartoum refinery.

\subsection{Methods}

Diesel characteristics usually were specified by government regulation, where properties and test methods were clearly specified. In the US, several government and state bodies can specify diesel properties, and they may choose to use or modify consensus minimum quality standards, such as American Society for Testing Materials (ASTM). The US diesel specifications and test methods were listed in several readily available publications, including the Society of Automotive Engineers (SAE), and the Annual Book of ASTM Standards.

\subsubsection{Physical Characteristics of Diesel Fuel}

(i) Standard test method for density of petroleum products

A small volume (approximately $0.7 \mathrm{~mL}$ ) of liquid sample was introduced into an oscillating sample tube and the change in oscillating frequency caused by the change in the mass of the tube was used in conjunction with calibration data to determine the density of the sample (ASTM., 2005).

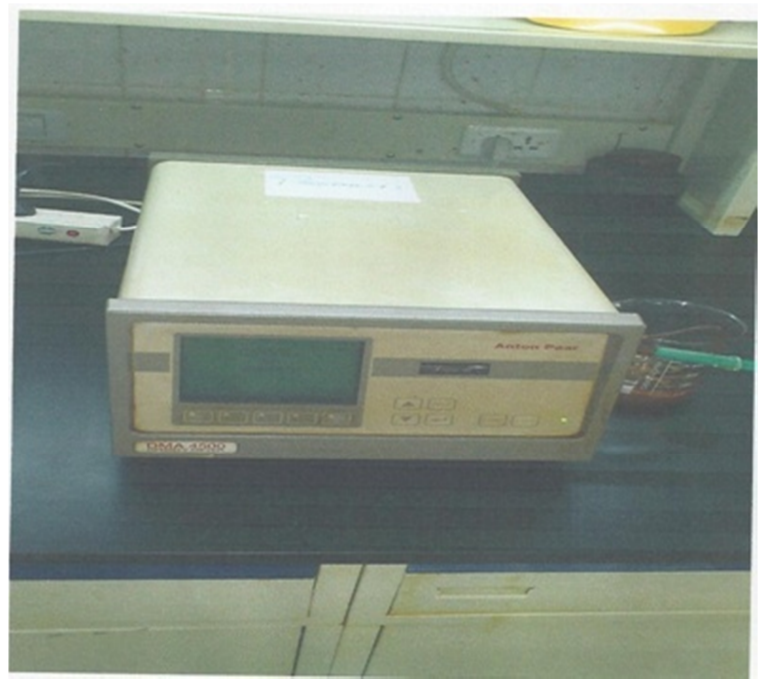

Fig. 1. Density apparatus at Khartoum refinery laboratory.

(ii) Standard test method for kinematic viscosity of diesel fuel

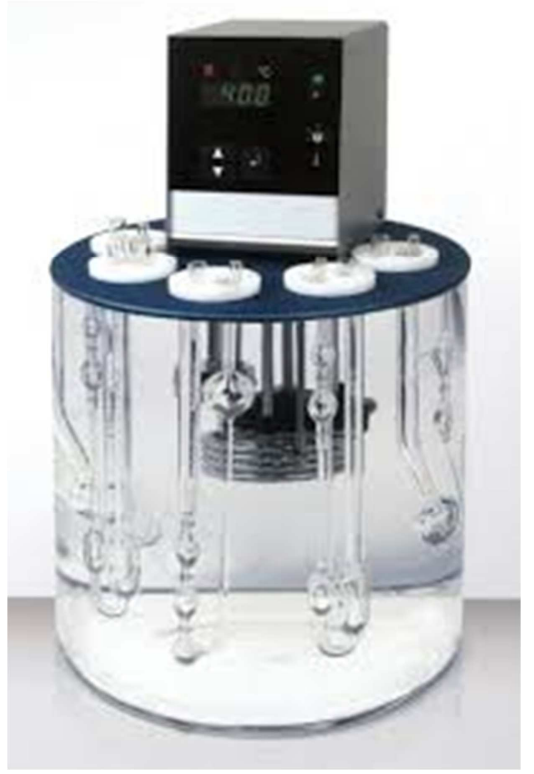

Fig. 2. Viscometer apparatus. 
The time was measured for a fixed volume of liquid to flow under gravity through the capillary of a calibrated viscometer under a reproducible driving head and at a closely controlled and known temperature. The kinematic viscosity was the product of the measured flow time and the calibration constant of the viscometer (ASTM, 2005) (Ezeldin, et al., 2015).

\subsubsection{Standard test Method for Cetane Number (CN) of Diesel Fuel}

The $\mathrm{CN}$ of diesel fuel oil was determined by comparing its combustion characteristics in a test engine with those for blends of reference fuel of known $\mathrm{CN}$ under standard operation conditions. This was accomplished using the bracketing hand wheel procedure wich varies the compression ratio (hand wheel reading ) for the sample and each of two bracketing reference fuels to obtain a specific ignition delay permitting interpolation of $\mathrm{CN}$ in term of hand wheel reading (ASTM, 2005).

\subsubsection{Passing of Diesel Fuel Sample on Magnetic Field}

The funnel was put on the center of magnetic stand $(121 \mathrm{mT})$ and conical flask was put under the stand, then a $200 \mathrm{~mL}$ of diesel fuel was passed on funnel and magnetic stand, the stop watch was starting.

\section{Results and Discussion}

In this project sample of diesel fuel used was produced from Khartoum refinery. Some physical properties and $\mathrm{CN}$ of sample are checked by applying many tests according to American Society for Testing and Materials (ASTM) before and after passing on magnetic field. These physical tests included: density and Viscosity. The experimental work was conducted at central laboratories of Khartoum refinery (Algily, north Khartoum) and central petroleum laboratories (CPL), Alamarat, str. 61, Khartoum.

\subsection{Density and Kinematic Viscosity of Diesel Sample Before and After Passing on Magnetic Field}

The density and viscosity properties of Diesel was Consideredvery important because decreased density and viscosity leads to increase the cetane number, it was important properties of diesel (Riazi and Al-Otaibi., 2000). The results of density and dynamic viscosity tests were shown in table 1 .

Table 1. Density and kinetic viscosity of diesel sample before and after passing on magnetic field.

\begin{tabular}{lll}
\hline Property & Before passage & After passage \\
\hline $\begin{array}{l}\text { Density }\left(\mathrm{g} / \mathrm{cm}^{3}\right) \\
\text { kinematic } \\
\text { viscosity }\left(\mathrm{mm}^{2} / \mathrm{s}\right)\end{array}$ & 0.8464 & 0.8244 \\
\hline
\end{tabular}

The obtained results in above table of density and kinematic viscosity for Diesel fuel sample give a strong indication that the quality of the diesel has been improved after passing the sample on magnetic field because the density and kinetic viscosity has been decreased, the reason of decreased the density and viscosity is attributed to the conversion some branched or ring compounds to liner hydrocarbon chain because the branched, cyclo and aromatic compounds considered of higher boiling points, densities and viscosities, also the decreased the density and viscosity may be attributed to extra oxidation is done and ultimately complete combustion at its optimum value is obtained. The obtained result before and after passage within the right permissible range assigned by the Khartoum refinery and ASTM. The above properties were measured at $40^{\circ} \mathrm{C}$ because this is the temperature of mixing the fuel and oxidant in internal combustion engines. The right permissible range assigned by Khartoum refinery according to American society for testing and materials ASTM was shown in Table 2.

Table 2. The right permissible limits assigned by Khartoum refinery according to ASTM.

\begin{tabular}{llll}
\hline properties & Temperature $^{\circ} \mathbf{C}$ & Summer & Winter \\
\hline $\begin{array}{l}\text { Density }\left(\mathrm{g} / \mathrm{cm}^{3}\right) \\
\begin{array}{l}\text { kinetic } \\
\text { viscosity }\left(\mathrm{mm}^{2} / \mathrm{s}\right)\end{array}\end{array}$ & 40 & $0.8063-0.9$ & $0.8063-0.9$ \\
\hline
\end{tabular}

The obtained results from density and kinematic viscosity tests were presented clearly in Fig 3. and Fig 4, respectively.

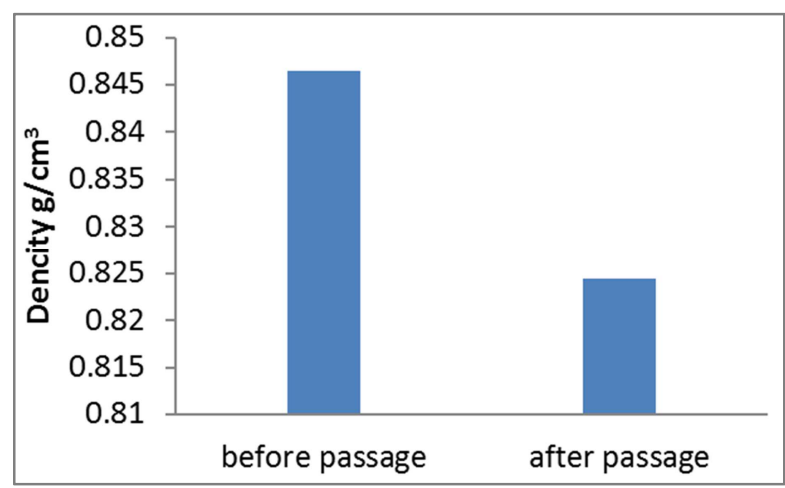

Fig. 3. The effect of magnetic field on density of diesel fuel sample.

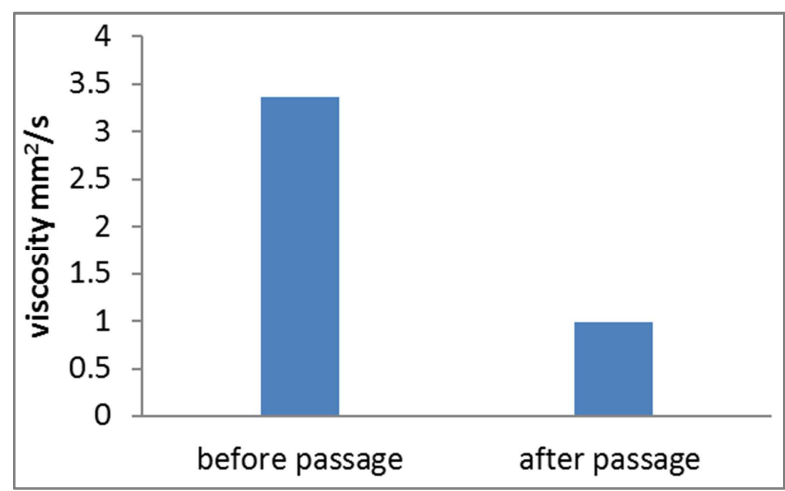

Fig. 4. The effect of magnetic field on kinematic viscosity of diesel fuel sample.

\subsection{Cetane Number (CN) of Diesel Fuel Sample}

The quality of diesel has been determined by $\mathrm{CN}$ value, 
therefore it was considered the important property of diesel fuel, the increase of $\mathrm{CN}$ that leads to decrease of Octane Number $(\mathrm{ON})$, therefore the $\mathrm{CN}$ and $\mathrm{ON}$ of the iso-octane equal zero and 100 respectively, but $\mathrm{CN}$ and $\mathrm{ON}$ of the n-heptane equal 100 and zero, respectively. The obtained results of $\mathrm{CN}$ test of diesel fuel sample were shown in Table 3.

Table 3. Cetane number of diesel fuel sample before and after passed on magnetic field.

\begin{tabular}{lll}
\hline property & Before passage on magnetic field & $\begin{array}{l}\text { After passed on } \\
\text { magnetic field }\end{array}$ \\
\hline $\mathrm{CN}$ & 56.6 & 60.3 \\
\hline
\end{tabular}

The obtained results in above table give good indication that the quality of the diesel has been improved after passing the sample on magnetic field because the $\mathrm{CN}$ was increased, the $\mathrm{CN}$ increase leads to increasing efficiency ignition therefore reduce the percentage of gases produced from the diesel machine exhaust. The reason for the increment of $\mathrm{CN}$ of diesel fuel sample after passing on magnetic field is due to the magnetic field effect on the structure of compounds comprising the diesel fuel, where the magnetic field may convert some cyclo, branched, and aromatics compounds to linear chain hydrocarbon, because the linear chain hydrocarbon show high cetane number.

The obtained results from the $\mathrm{CN}$ test were presented clearly in Fig 5.

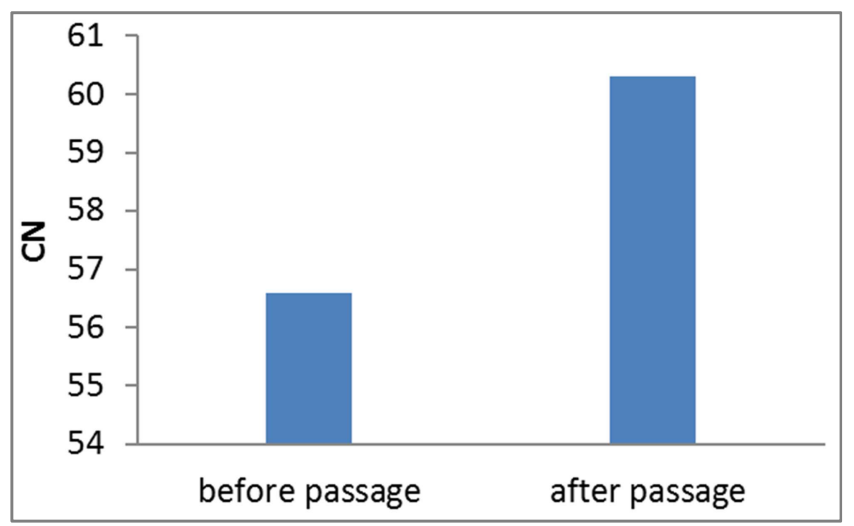

Fig. 5. The effect of magnetic field on CN of diesel fuel sample.

\section{Conclusion}

Based on the previously discussed experimental results the following conclusions can be summarized as.

- The CN of diesel fuel sample used in this project was found to be 56.6 .

- The CN of diesel fuel sample was increased to 60.3.

- The magnetic field has profound effect in improving $\mathrm{CN}$ of diesel fuel sample produced from Khartoum Refinery.

- The density and kinematic viscosity properties for diesel fuel before and after passed on magnetic field were found within the range assiging by Khartoum refinery.

\section{Acknowledgement}

Above all, praise is to $G O D$ who has sustained me throughout this work. I would like, prof. Hatel H. Alkamali, Dean of faculty of science and technology, Omdurman Islamic university. Special thanks also expressed to prof. Mohammed Hmaad, Mr. Omer A. Goda, Mrs. Esraa Ahmed and all staff at Al Khartoum Refinery Laboratory. Also, my thanks and gratitude extended to the staff of Central Petroleum Laboratories. Special thanks to our colleagues at faculty of Science and Technology - Chemistry Lab. for theirs helpful assistance and providing the required equipments and materials to complete this work. Finally, I extend my grateful thanks to all who helped me during the period of my research.

\section{References}

[1] Annual book of ASTM standards. (2005). American Society for Testing and Materials. West Conshohocken: Salvter. J. Rand.

[2] Davis, A.M.J., Brenner, H. (2001). The Cetane Number. Phys. Fluids, 13: (4), 3086-3088.

[3] Duncan, A.M., et al. (2012). High-pressure viscosity of soybean-based diesel blends with ultra-low sulfur diesel fuel. Energy Fuels, 26(5), 7023-7036.

[4] Duncan, A.M., et al. (2010). High-pressure viscosity of diesel from Soybean, Canola, and Canola Oils. Energy Fuels, 24(2), 5708-5716.

[5] Ezeldin, M., Masaad, A, M., Abualreish, M, J, A. (2015). Quality improvement of reformat gasoline by using aniline and toluene. International Journal of Current Research, 7(9): 20531-20538.

[6] Govindasamy, p., Dhandapanis, p. (2007). Experimental Investigation of Cyclic Variation of Combustion Parameters in Catalytically Activated and Magnetically Energized Twostroke SI Engine. journal of scientific and industrial research, $66(2), 457-463$

[7] Gruse, W, A., Stevens, D. R. (1960).chemical Technology of petroleum, 3th rd. Newyork: McGraw. Hill Book compony, P 42.

[8] Harris, K.R., Kanakubo, M., Woolf, L.A. (2007). Temperature and pressure dependence of the viscosity of the ionic liquids 1-hexyl-3-methylimidazolium hexafluorophosphate and 1butyl-3-methylimidazolium bis (trifluoromethylsulfonyl) imide. J. Chem. Eng. Data, 52: (3), 1080-1085.

[9] Isdale, J. (1976). Cetane Number of Simple Liquids including Measurement and Prediction at Elevated Pressure. Ph.D. Thesis, University of Strathclyde, Glasgow, UK.

[10] Lee, S, W., et al. (2002). Effects of diesel fuel characteristics on spray and combustion in a diesel engine. JSAE Rev. 23: (3), 407-414.

[11] Park, N.A., Irvine, T.F. (1984). The falling needle viscometer-A new technique for viscosity measurements. Warme Stoffubertrag, 18(1), 201-206. 
[12] Riazi, M.R., Al-Otaibi, G.N (2000). Estimation of viscosity of liquid hydrocarbon systems. Fuel. 80: (5), 27-32.

[13] Yamaki, Y., et al. (2001). Heavy Duty Diesel Engine with Common Rail Type Fuel Injection Systems. Japanese Society of Automotive Engineers: Tokyo, Japan, 1995.
[14] Gruse, W, A., Stevens, D. R. (1960). chemical Technology of petroleum, 3thrd. Newyork: McGraw. Hill Book compony, P 42-472. 